\title{
Criatividade e escola: limites e possibilidades segundo gestores e orientadores educacionais
}

\author{
Eny da Luz Lacerda Oliveira \\ Eunice Maria Lima Soriano de Alencar
}

\begin{abstract}
Resumo
Este estudo investigou concepções de criatividade e importância atribuída a ela por gestores e orientadores educacionais, bem como elementos inibidores e facilitadores à implementação de práticas pedagógicas para o desenvolvimento da criatividade e à intervenção desses profissionais no sentido de promover a criatividade na organização escolar. Nove gestores e 10 orientadores educacionais foram entrevistados, utilizandose análise de conteúdo para exame dos dados. Constatou-se que, embora esses profissionais considerassem a criatividade importante, o conhecimento que embasava sua prática advinha do senso comum. Os elementos inibidores e facilitadores à implementação de práticas pedagógicas para o desenvolvimento da criatividade mais destacados foram de natureza pessoal/pedagógica relacionados ao professor, seguidos dos de natureza administrativa. Os elementos inibidores à intervenção de gestores e orientadores educacionais em prol do desenvolvimento da criatividade na escola mais frequentemente apontados foram referentes ao docente e à família, ao passo que, entre os facilitadores, houve destaque para os relativos às suas funções.
\end{abstract}

Palavras-chave: Criatividade, gestão Escolar, orientação educacional.

\section{Creativity and School: Limits and Possibilities according to School Principals and School Counselors}

\begin{abstract}
This study investigated conceptions of creativity and its importance according to school principals and school counselors, inhibiting and facilitating elements to the implementation of teaching practices for creativity and to the intervention of these professionals to promote creativity in school. Nine school principals and 10 school counselors were interviewed. Data were analyzed through content analysis. Results indicated that, although these professionals attributed importance to creativity, the creativity knowledge that based their practice was from the common sense. The most prominent inhibiting and facilitating elements to the implementation of practices for creativity development were those of personal / pedagogical nature related to the teacher, and those of administrative nature. The inhibiting elements to the intervention of these professionals to support the educational development of creativity in school more frequently pointed out were those related to the teacher and to the family, while the most frequent facilitators were related to their functions.
\end{abstract}

Keywords: Creativity, school administration, educational counseling.

\section{Creatividad y escuela: límites y posibilidades según gestores y orientadores educacionales}

\begin{abstract}
Resumen
Este estudio investigó conceptos de creatividad y la importancia que gestores y orientadores educacionales les atribuyen, elementos inhibidores y facilitadores para la implementación de prácticas pedagógicas para el desarrollo de la creatividad y para la intervención de esos profesionales en el sentido de promover la creatividad en la organización escolar. Se entrevistaron nueve (09) gestores y diez (10) orientadores educacionales, utilizando análisis de contenido para examinar los datos. Se constató que a pesar de que los profesionales considerasen la creatividad importante, el conocimiento que subsidiaba su práctica provenía del sentido común. Los elementos inhibidores y facilitadores para la implementación de prácticas pedagógicas para el desarrollo de la creatividad más destacados fueron de naturaleza personal/pedagógica relacionados al profesor, seguidos de los de naturaleza administrativa. Los elementos inhibidores a la intervención de gestores y orientadores educacionales en pro del desarrollo de la creatividad en la escuela más frecuentemente señalados se refirieron al docente y a la familia, al paso que entre los facilitadores, hubo destaque para los relacionados a sus funciones.
\end{abstract}

Palabras-clave: Creatividad, gestión escolar, orientación educacional. 


\section{Introdução}

A criatividade está presente nos vários segmentos da vida humana, em especial no campo do trabalho e da educação, constituindo-se em um recurso essencial para que o indivíduo possa enfrentar de modo eficaz os conflitos, tensões e exigências do mundo contemporâneo. Este, como se sabe, caracteriza-se por constantes desafios impostos pela globalização, mundialização da cultura, provisoriedade do conhecimento e mudanças contínuas nas relações de trabalho e de produção (Castells, 1999, 2003; Hill, 2003; Ortiz, 1994; Rifkin, 2000; Smith-Bingham, 2007; Touraine, 1994).

Observa-se que a criatividade tem sido objeto de estudo de muitas áreas do conhecimento como a Psicologia, a Sociologia, a Filosofia, a História e a Antropologia, tendo sido investigada a partir de pontos de vista e modelos teóricos diferentes (Martínez, 2003; Runco, 2007; Saywer, 2006). Inúmeras definições já foram propostas para esse termo, embora exista um consenso entre distintos estudiosos, ao considerar que "a criatividade pressupõe uma pessoa que, em determinadas condições e por intermédio de um processo, elabora um produto que é, pelo menos em alguma medida, novo e valioso" (Martínez, 2003, p. 9). Contudo, Csikszentmihalyi (1994) ressalta que, se queremos entender a criatividade, nós devemos pesquisá-la fora dos limites da pessoa individual e, assim, o autor apresenta um novo questionamento como foco central para os estudos da criatividade. Ao invés da usual pergunta o que é criatividade?, o autor sugere: onde está a criatividade? Com base em seu modelo sistêmico que destaca as forças sociais, culturais e pessoais para explicar o fenômeno da criatividade, Csikszentmihalyi evidencia que a criatividade não está restrita às mentes, ou seja, não se deve entendê-la e explicá-la somente em função das operações cognitivas, pois a criatividade é o resultado da interação entre o pensamento das pessoas e o contexto sociocultural.

Vale lembrar que a criatividade pode ser desenvolvida e a escola é um espaço privilegiado, por sua natureza educativa, para promover o desenvolvimento e expressão das habilidades criativas daqueles que a frequentam. Neste sentido, Alencar (2009) e Alencar e Fleith (2003) ressaltam que as habilidades criativas são de crucial importância no processo de preparação dos alunos para lidar com o mundo complexo e cheio de desafios. Contudo, percebe-se que a criatividade no contexto educacional, em geral, tem tomado como base para reflexão o senso comum e, assim, seu verdadeiro significado e implicações pedagógicas deixam de ser evidenciados. Essa situação pode levar à banalização da criatividade, que dessa forma será tratada com simplismo e permeada por mitos e crenças que lhe conferirão uma visão restrita. Ademais, Alencar e Fleith (2003) salientam que, na escola, é comum dar relevância à ignorância e à incompetência do aluno e, em contrapartida, não se enfatizam suas potencialidades quanto ao talento e às habilidades individuais, criando, assim, barreiras ao desenvolvimento da criatividade. É comum, ainda, uma educação voltada excessivamente para o passado, enfatizando a reprodução de conhecimento e a memorização dos ensinamentos.
Em que pese toda a complexidade que envolve o fenômeno da criatividade, é importante lembrar que a prática pedagógica pode e necessita ser repensada por toda a comunidade educativa, pois, conforme Martínez (2003, p. 141), "o progresso e a complexidade que a humanidade alcançou no âmbito socioeconômico, nas artes, na tecnologia e na ciência despertou o interesse pela criatividade e seu desenvolvimento". Assim, o reconhecimento e a importância que esse tema tem adquirido no mundo contemporâneo exigem ações educativas estratégicas e práticas que favoreçam o desenvolvimento do potencial criador dos alunos.

Nesse cenário, gestores e orientadores educacionais desempenham papéis de relevância dentro da escola, uma das esferas de produção de capacidade de trabalho, que é um dos principais elementos de inserção social.

No caso do gestor, a LDB - Lei de Diretrizes e Bases -, em seu artigo 14, determina que os sistemas de ensino públicos definam as normas de gestão na Educação Básica de acordo com as suas peculiaridades e conforme os seguintes princípios: I. participação dos profissionais da educação na elaboração do projeto pedagógico da escola; II. participação das comunidades escolar e local em conselhos escolares ou equivalentes (Brasil, 1996).

No Art. 15, os sistemas de ensino assegurarão, às unidades escolares públicas de Educação Básica que os integram, progressivos graus de autonomia pedagógica e administrativa e de gestão financeira, observadas as normas de direito financeiro público.

No tocante à gestão escolar, Lück (2000) ressalta que o diretor, em seu papel, é gestor da dinâmica social; mobilizador, articulador da diversidade para dar-Ihe consistência e unidade; e responsável por promover transformações de relações de poder, de práticas e da organização escolar.

Ainda, para esta autora, o bom gestor deve ter uma visão da escola inserida em sua comunidade, a médio e longo prazo, com horizontes largos, e ainda compartilhar o poder e a tomada de decisões de forma coletiva.

A esse respeito, Lück e cols. (2001) esclarecem que, no final da década de 1970, os educadores e pesquisadores de todo o mundo voltaram sua atenção para o impacto que uma gestão participativa pode causar no que se refere à eficácia das escolas como organizações.

Daí a importância desse personagem escolar, que tem uma posição central e cujas ações sustentam o bom andamento das atividades propostas, a eficácia organizacional e o sucesso das ações planejadas.

Quanto ao orientador educacional, suas atribuições ultrapassam os muros da escola e refletem diretamente nas questões sociais, especialmente as que dizem respeito à profissionalização dos educandos e seu ingresso no mercado de trabalho. Ele tem atribuições privativas as quais cabe a ele coordenar e outras de caráter participativo junto aos demais membros da equipe escolar, família e comunidade, o que o configura como um dos grandes responsáveis pelo bem-estar daqueles a que, direta ou indiretamente, suas ações atingem, denotando, desse modo, a dimensão política de sua atuação. Este personagem escolar encontra-se em 
posição de destaque no processo de ensino-aprendizagem e de formação integral do aluno para o exercício da cidadania, configurando-se, também, como elemento-chave para o desenvolvimento da expressão criativa no contexto escolar.

Observa-se que há uma vasta literatura sobre criatividade no contexto educacional, com inúmeros estudos realizados com amostras de estudantes e professores dos distintos níveis de ensino (Alencar \& Fleith, 2003; Craft, 2005; Cropley, 1997, 2005; Jackson, Oliver, Shaw \& Wisdom, 2007; Martínez, 2002, 2006; Nakano \& Wechsler, 2007; Starko, 1995; Wechsler, 2001, 2002). Entretanto, há escassez de estudos empíricos com dados coletados junto a profissionais que fazem parte da equipe pedagógica, para além do docente. Diante desta realidade, objetivou-se investigar como gestores e orientadores educacionais vêm lidando com a criatividade no contexto escolar, priorizando as seguintes questões: Qual a concepção de criatividade desses profissionais e a importância pessoal e social atribuída por eles à criatividade? Que elementos consideram como inibidores e facilitadores à implementação de práticas pedagógicas voltadas para o desenvolvimento da criatividade escolar? No exercício da função de gestores e orientadores educacionais, que elementos constituem-se em inibidores ou facilitadores a uma intervenção no sentido de promover condições favoráveis ao desenvolvimento da criatividade da própria organização escolar e de seus integrantes?

\section{Método}

\section{Participantes}

Participaram do estudo nove gestores e 10 orientadores educacionais atuantes em 10 escolas de Ensino Fundamental da rede de escolas públicas da Secretaria de Estado de Educação do Distrito Federal, todas localizadas no Plano Piloto, área central de Brasília. Todos os gestores eram do sexo feminino, com idade variando entre 35 a 47 anos e tempo de experiência na função entre 1 e 12 anos, tendo seis deles concluído o curso de especialização e os demais, graduação.

Entre os orientadores educacionais, nove eram do sexo feminino e um, do sexo masculino, com idade variando de 34 a 60 anos. Quanto à escolaridade, cinco haviam concluído curso de graduação e os demais, especialização, variando o seu tempo na função entre 4 e 27 anos.

\section{Instrumento}

Utilizou-se a entrevista semiestruturada que se constituiu de três partes. A primeira para levantamento de dados pessoais (gênero, idade, tempo na função e formação). A segunda com questões relativas a(o): a) conceito de criatividade e sua importância pessoal e social; b) elementos inibidores e facilitadores de diversas naturezas (política, administrativa, material, entre outras) que interferem na implantação de práticas pedagógicas voltadas para o desenvolvimento da criatividade no contexto escolar; c) possibilidade do gestor/ orientador educacional contribuir para o desenvolvimento da criatividade no contexto escolar; d) elementos que facilitam ou inibem, no exercício da função de gestor/orientador educacional, uma intervenção no sentido de promover condições favoráveis ao desenvolvimento da criatividade na escola e de seus integrantes; e) oportunidade de contato com a literatura ou participação em cursos palestras, seminários, entre outros, sobre criatividade. A terceira parte constituiu-se em espaço livre para a expressão do entrevistado a respeito de outros tópicos que julgasse relevante no tocante às questões abordadas na entrevista. Utilizou-se como guia um protocolo de entrevista, mas o curso do diálogo foi algumas vezes alterado em função das respostas dos participantes.

\section{Procedimentos}

Os profissionais (gestores e orientadores educacionais) foram contatados diretamente em seus postos de trabalho pela primeira autora, ocasião em que foram prestados esclarecimentos acerca da realização e dinâmica da entrevista, dos objetivos deste estudo, da garantia do sigilo, do anonimato e do uso do gravador. A participação foi voluntária, tendo os participantes sido informados de que os dados seriam analisados coletivamente, cumprindo-se as exigências éticas legais. As entrevistas, que tiveram duração média de 41 minutos, foram gravadas em áudio e transcritas verbatim.

Antes da coleta definitiva dos dados, realizou-se um estudo piloto, que contou com a participação de um gestor e de um orientador educacional. Após a realização do referido estudo, duas questões foram incluídas no protocolo de entrevista, a saber: a) para você o que é criatividade? e b) você já teve oportunidade de participar de cursos, palestras, seminários, entre outros, sobre criatividade ou já entrou em contato com a literatura sobre esse tema? Considerou-se que, a partir das respostas às novas questões, algumas opiniões, modos de pensar e posicionamentos explicitados pelos entrevistados a outros questionamentos seriam meIhor entendidos, avaliados e esclarecidos.

\section{Análise dos dados}

Utilizou-se a técnica da análise de conteúdo na perspectiva de diversos autores (Bardin, 1995; Bauer \& Gaskell, 2002; Franco, 2005; Richardson, 1999). Realizou-se a análise de conteúdo, obedecendo-se às seguintes etapas: a) préanálise e organização preliminar do material como forma de clarificar, organizar e sistematizar as ideias, tornando o material operacional; b) exploração do material, privilegiandose o tema como unidade de registro e definindo-se as regras de numeração e categorização, baseadas nas questões formuladas, procedendo à montagem dos quadros; c) tratamento dos resultados, inferência e interpretação. Para cada 
Tabela 1. Concepções de criatividade apresentadas por gestores e orientadores educacionais.

\begin{tabular}{|c|c|c|c|c|}
\hline & $\mathrm{G}^{*}$ & O.E* & \multicolumn{2}{|c|}{ Total } \\
\hline CONCEPÇÕES & f & $f$ & $f$ & $\%$ \\
\hline $\begin{array}{l}\rightarrow \text { CRIATIVIDADE COMO PRODUTORA DO NOVO E DO DIFERENTE } \\
\text { - É inovação, é pensar diferente }{ }^{1} \\
\text { - Permite a quebra paradigmas, padrões e convenções } \\
\text { - Meio de se trabalhar não imitando outros anteriores } \\
\text { - É sempre fazer alguma coisa nova para melhorar o que já está feito } \\
\text { - Fazer diferente, sair da mesmice, criar opções } \\
\text { - Encontrar outro modelo de resposta }\end{array}$ & 3 & 4 & 7 & 30,43 \\
\hline $\begin{array}{l}\text { I CRIATIVIDADE COMO GERADORA DE SOLUÇÕES } \\
\text { - Criar algo no momento que você está precisando } \\
\text { - Conseguir superar obstáculos do momento } \\
\text { - Conseguir achar outras soluções }\end{array}$ & 5 & 2 & 7 & 30,43 \\
\hline \begin{tabular}{|l} 
- CRIATIVIDADE COMO ATRIBUTO PESSOAL \\
- Aprender a andar de acordo com as situações da vida e ser \\
autônomo \\
- Ter jogo de cintura \\
- Ser capaz de se adaptar e buscar soluções rápidas \\
- Ser capaz de articular informações em busca de soluções \\
- Buscar a melhor maneira de crescer e fazer com que o outro cresça
\end{tabular} & 4 & 2 & 6 & 26,09 \\
\hline \begin{tabular}{|l}
$\rightarrow$ CRIATIVIDADE ASSOCIADA À ARTE \\
- A criatividade através da arte é muito mais ampla \\
- O professor criativo é o que manuseia esse lado artístico
\end{tabular} & 0 & 2 & 2 & 8,70 \\
\hline $\begin{array}{l}\rightarrow \text { CRIATIVIDADE COMO UM ELEMENTO DE PRAZER } \\
\text { - Não existe criatividade sem prazer }\end{array}$ & 0 & 1 & 1 & 4,35 \\
\hline TOTAL & 12 & 11 & 23 & $100 \%$ \\
\hline
\end{tabular}

* Gestor ** Orientador Educacional

Nota: A porcentagem foi calculada conforme o número de concepções explicitadas por gestores e orientadores educacionais e não a partir do número de entrevistados.

categoria, foram calculadas as ${ }^{1}$ frequências e porcentagens de respostas.

\section{Resultados e Discussão}

\section{Concepções de gestores e orientadores educacionais sobre criatividade}

Como pode ser observado, na Tabela 1, as respostas dos participantes referentes às concepções de criatividade 1 Ressaltamos que as expressões contidas nas tabelas não retratam na sua integralidade as falas dos entrevistados. distribuíram-se nas seguintes categorias: criatividade como produtora do novo e do diferente; criatividade como geradora de soluções; criatividade como um atributo pessoal; criatividade como elemento de prazer; criatividade associada à arte.

Seguem exemplos de respostas que ilustram algumas das categorias identificadas:

É fazer o diferente, né? Inovar, pensar diferente, ter um outro olhar diferente, [...] produzir diferente, colocar em prática. $(\mathrm{OE} 1)^{2}$

É você conseguir achar outras soluções, de outro jeito,

2 (OE) Orientador Educacional 
Tabela 2. Razões explicitadas por gestores e orientadores educacionais para justificar a importância pessoal da criatividade.

\begin{tabular}{|c|c|c|c|c|}
\hline & $\mathrm{G}$ & O.E & \multicolumn{2}{|c|}{ Total } \\
\hline RAZÕES EXPLICITADAS & $f$ & $f$ & $f$ & $\%$ \\
\hline $\begin{array}{l}\text { - RELACIONADAS AO MERCADO DE TRABALHO } \\
\text { - Pessoas criativas, profissionalmente, se dão melhor na vida } \\
\text { - Se você não se sobressair, o mercado não vai absorvê-lo } \\
\text { - Para não ficar fora do mercado } \\
\text { - Pra você aparecer, ter mais chances no mercado de trabalho } \\
\text { - Porque torna-se mais fácil ficar bem no mercado de trabalho }\end{array}$ & 4 & 7 & 11 & 25,00 \\
\hline $\begin{array}{l}\text { - RELACIONADAS À SOBREVIVÊNCIA DO INDIVÍDUO } \\
\text { - É uma habilidade básica para a sobrevivência do ser humano } \\
\text { - Se a gente não for criativa, não sobrevive } \\
\text { - Na questão pessoal, é uma forma de sobreviver nesse mundo }\end{array}$ & 4 & 7 & 11 & 25,00 \\
\hline $\begin{array}{l}\text { - RELACIONADAS AO CRESCIMENTO PESSOAL } \\
\text { - Para tirar você do estágio estacionário, levar à movimentação } \\
\text { - Para estabelecer um estágio de felicidade, crescer } \\
\text { - Serve para sair da mesmice, da reprodução, da padronização, } \\
\text { - Para levar à reflexão, ao crescimento }\end{array}$ & 5 & 3 & 8 & 18,19 \\
\hline $\begin{array}{l}\rightarrow \text { RELACIONADAS À CONVIVÊNCIA } \\
\text { - Para aprender a lidar com as pessoas } \\
\text { - Para facilitar as relações interpessoais } \\
\text { - Para viver em comunidade } \\
\text { - Para se relacionar melhor com as pessoas, fazer amigos } \\
\text { - Em termos de convivência, de paz }\end{array}$ & 3 & 4 & 7 & 15,90 \\
\hline $\begin{aligned} \rightarrow & \text { RELACIONADAS À ADAPTAÇÃO DO INDIVÍDUO } \\
& \text { - Serve para se adaptar aos diversos ambientes e situações }\end{aligned}$ & 0 & 4 & 4 & 9,09 \\
\hline $\begin{array}{l}\rightarrow \text { RELACIONADAS À SUPERAÇÃO DA ROTATIVIDADE } \\
\text { - São muitas informações, os problemas precisam de respostas } \\
\text { rápidas } \\
\text { - É muita rotatividade e muita informação que precisa ser assimilada }\end{array}$ & 3 & 0 & 3 & 6,82 \\
\hline TOTAL & 19 & 25 & 44 & $100 \%$ \\
\hline
\end{tabular}

Nota: A porcentagem foi calculada conforme o número de respostas emitidas por gestores e orientadores educacionais e não a partir do número de entrevistados.

para resolver aquele problema, [...] ser rápido pra resolver achando soluções de outro modo. (G4)

Idealizar e realizar alguma coisa que te dá prazer. Eu acho que não existe criatividade sem prazer, as duas coisas andam juntas. (OE5)

Observou-se, durante a entrevista, que tanto com relação aos gestores quanto aos orientadores educacionais,

3 (G) Gestor as respostas vinham acompanhadas de pausa, reflexões evasivas ou exemplos de atos criativos, denotando certa insegurança em emitir conceitos ou definições sobre este fenômeno. Tal fato corrobora, em alguma medida, o que vários pesquisadores (Alencar \& Fleith, 2003; Edwards, McGoldrick \& Oliver, 2007; Feldman, Csikszentmihalyi \& Gardner, 1994; Martínez, 2003; Prado-Diez, 1999) dessa área ressaltaram, ou seja, a criatividade é inerente a todo ser humano e pode se manifestar em todos os setores, contudo, defini-la ou conceituá-la de forma precisa e concreta é tarefa difícil, visto 
que ela se constitui em um fenômeno complexo, difuso, multifacetado e plurideterminado.

Ao serem questionados sobre seu contato com a literatura sobre criatividade, participações em eventos, realização de cursos, entre outros, que tratavam dessa temática, somente dois gestores informaram ter realizado algumas leituras e um orientador educacional mencionou ter assistido a duas palestras. Este fato sugere que o conhecimento que vem permeando as ações diárias desses profissionais é o do senso comum, o que não lhes permite ações intencionais, mas sim intuitivas, já que os dados da pesquisa apontam para um conhecimento limitado de técnicas, procedimentos docentes ou práticas pedagógicas que possibilitam a produção de ideias que visem ao desenvolvimento do potencial criativo dos educandos, bem como do ambiente escolar. No entanto, apesar de as concepções dos entrevistados terem como base o senso comum, elas satisfazem, ao menos em alguma medida, a ideia que parece coexistir entre os especialistas na área de que a criatividade implica a emergência de um produto novo, original e que seja apropriado a uma determinada situação, já que vários participantes a consideraram como produtora do novo e do diferente e capaz de gerar soluções para os problemas emergentes.

Esclarecemos que, por senso comum, entendemos o conhecimento advindo de experiências e vivências cotidianas, individuais e coletivas.

\section{Importância pessoal da criatividade segundo gestores e orientadores educacionais}

As respostas à questão relativa à importância pessoal da criatividade distribuíram-se em seis categorias relacionadas a: mercado de trabalho; sobrevivência do indivíduo; convivência; possibilidade de crescimento pessoal; superação da rotatividade do mundo atual; adaptação do indivíduo (ver Tabela 2).

As seguintes falas ilustram distintas categorias:

Se você quer uma profissão em ascensão, quer o melhor pra sua vida, você tem que ser criativo, [...] eu acho que é importante, é essencial. Quer ver? As pessoas criativas, normalmente, profissionalmente, elas se dão melhor na vida. (G4)

Levaa pessoaa pensarpara entenderoque estáacontecendo, [...] para levá-la a uma reflexão, ao crescimento. (OE1)

O mundo hoje é tão rápido, a coisa acontece de tal maneira que, se não for uma pessoa muito criativa, ela vai ficar para trás. É muita rotatividade, muita informação que precisa ser assimilada. (G5)

A importância pessoal da criatividade foi corroborada por todos os respondentes da pesquisa, resultado esperado, haja vista que desenvolver a criatividade é um dos discursos que hoje permeia o contexto escolar.
Observou-se que, de modo geral, os entrevistados, ao se referirem à relação entre criatividade e mundo do trabalho, o fizeram com muita veemência, denotando a convicção de que ela é um diferencial que, nos dias atuais, o profissional precisa possuir. Essa percepção nos remete a Alencar (1996, 2000a), Craft (2007) e Zhou e Shalley (2008), entre outros autores, que ressaltam que as organizações de distintos países vêm investindo significativamente em programas de criatividade.

\section{Importância social da criatividade segundo gestores e orientadores educacionais}

A esse respeito, a análise das respostas (ver Tabela 3 ) indicou que as mesmas se distribuíram em sete categorias relacionadas a: desenvolvimento e evolução; bem-estar coletivo e social; fenômeno contagiante; convivência social; funções de liderança e coordenação; sobrevivência social; emprego.

Seguem respostas que retratam distintas categorias identificadas:

Eu acho que esse pensamento criativo, esse olhar criativo que faz a gente crescer [...] é o olhar criativo que torna o desenvolvimento possível. (OE4)

A criatividade promove boas relações, [...] uma pessoa criativa vai servir de elo entre as pessoas, [...] a função dela na sociedade é mesmo facilitar essas relações, é uma facilitadora das relações sociais. (G3)

Os grandes segmentos, os que se sobressaem, é porque os líderes são criativos. (G7)

Eu acho que é também questão de sobrevivência. A gente escuta que só se cria uma coisa nova em situação de crise. Eu acho que talvez a gente nunca tenha vivenciado tanta crise como agora, por isso que as respostas têm que ser rápidas. (OE5)

A criatividade é importante para a sociedade! Você cria meios de trabalho. (OE8)

Se o momento histórico atual caracteriza-se por intensas mudanças, quando as incertezas permeiam a vida em sociedade e a provisoriedade do conhecimento está posta, exigindo uma aprendizagem contínua e permanente e se não é possível prever com exatidão que conhecimento será necessário no futuro, é indispensável o desenvolvimento de habilidades que ajudem o indivíduo a se adaptar com maior facilidade às condições impostas pelo mundo contemporâneo (Alencar \& Fleith, 2003; Gilson, 2008). É em virtude desse contexto que a criatividade tem sido apontada como uma habilidade de sobrevivência, como um recurso para lidar com os problemas que se apresentam diariamente, tanto em volume quanto em complexidade. Esse fato foi reconhecido 
Tabela 3. Razões explicitadas por gestores e orientadores educacionais para justificar a importância social da criatividade

\begin{tabular}{|c|c|c|c|c|}
\hline & $G$ & O.E & \multicolumn{2}{|c|}{ Total } \\
\hline RAZÕES EXPLICITADAS & $f$ & $f$ & $f$ & $\%$ \\
\hline $\begin{array}{l}\rightarrow \text { RELACIONADAS AO DESENVOLVIMENTO E À EVOLUÇÃO } \\
\text { - É a partir dela que surgem novas experiências, é a base da evolução } \\
\text { - A criatividade faz com que a sociedade cresça, seja diferente } \\
\text { - Permite a evolução da sociedade } \\
\text { - Torna o desenvolvimento possível }\end{array}$ & 7 & 4 & 11 & 33,34 \\
\hline $\begin{array}{l}\rightarrow \text { RELACIONADAS AO BEM-ESTAR SOCIAL } \\
\text { - O bem-estar social está nas mãos dos seres criativos } \\
\text { - Serve para gerar uma sociedade mais saudável } \\
\text { - Para criar condições para o pensar no outro, o viver bem } \\
\text { em sociedade } \\
\text { - Para melhorar a vida das pessoas }\end{array}$ & 4 & 4 & 8 & 24,24 \\
\hline $\begin{array}{l}\rightarrow \text { RELACIONADAS AO ASPECTO CONTAGIANTE DA } \\
\text { CRIATIVIDADE } \\
\text { - O ser criativo transmite vitalidade para realizações } \\
\text { - Provoca inquietude } \\
\text { - Vai criando novas pessoas criativas, virando uma rede dentro da } \\
\text { sociedade, uma rede criativa }\end{array}$ & 2 & 2 & 4 & 12,12 \\
\hline $\begin{array}{l}\rightarrow \text { RELACIONADAS À CONVIVÊNCIA SOCIAL } \\
\text { - Com pessoas criativas, a sociedade ganha no relacionamento } \\
\text { - A criatividade promove boas relações }\end{array}$ & 4 & 0 & 4 & 12,12 \\
\hline $\begin{array}{l}\rightarrow \text { RELACIONADAS ÀS FUNÇÕES DE LIDERANÇA E } \\
\text { COORDENAÇÃO } \\
\text { - Os segmentos que se sobressaem têm líderes criativos }\end{array}$ & 2 & 0 & 2 & 6,06 \\
\hline $\begin{array}{l}\rightarrow \text { RELACIONADAS À SOBREVIVÊNCIA SOCIAL } \\
\text { - Questão de sobrevivência, para dar respostas rápidas às crises sociais } \\
\text { - Serve pra você utilizar um recurso natural sem destruir a natureza }\end{array}$ & 0 & 3 & 3 & 9,09 \\
\hline $\begin{array}{l}\rightarrow \text { RELACIONADAS AO EMPREGO } \\
\text { - Serve para criar meios de trabalho }\end{array}$ & 0 & 1 & 1 & 3,03 \\
\hline TOTAL & 19 & 14 & 33 & $100 \%$ \\
\hline
\end{tabular}

Nota: A porcentagem foi calculada conforme o número de respostas emitidas por gestores e orientadores educacionais e não a partir do número de entrevistados.

pelos entrevistados deste estudo ao se referirem ao acúmulo de informações, à rotatividade dos acontecimentos e à necessidade de respostas rápidas impostas pelo mundo atual, elementos que requerem, segundo eles, muita criatividade.

As habilidades criativas de um povo influirão, de forma marcante, no desenvolvimento da sociedade a qual ele pertence, fenômeno social também percebido pelos respondentes, visto que todos reconheceram a importância social da criatividade. Ademais, foi considerada, ainda, como fator de sobrevivência da sociedade. 
Tabela 4. Elementos inibidores à implementação de práticas pedagógicas voltadas para a criatividade segundo gestores e orientadores educacionais.

\begin{tabular}{|c|c|c|c|c|}
\hline & G & O.E & \multicolumn{2}{|c|}{ Total } \\
\hline ELEMENTOS INIBIDORES & $f$ & $f$ & $f$ & $\%$ \\
\hline $\begin{array}{l}\text { T DE NATUREZA PESSOAL/PEDAGÓGICA RELACIONADOS AO PROFESSOR } \\
\text { - Desestímulo, desânimo, falta de comprometimento dos docentes } \\
\text { - Falta de capacitação profissional, formação tradicional, } \\
\text { conservadorismo } \\
\text { - Medo do novo, de criar opções, por parte dos professores } \\
\text { - Sentimento de desvalorização pelo profissional da educação } \\
\text { - Parece que os alunos sabem mais que os professores } \\
\text { - O aluno está muito mais avançado, tecnologicamente, que o } \\
\text { professor }\end{array}$ & 16 & 21 & 37 & 45,13 \\
\hline $\begin{array}{l}\rightarrow \text { DE NATUREZA ADMINISTRATIVA } \\
\text { - Rotatividade de professores } \\
\text { - Falta de material } \\
\text { - Rigidez das normas, cumprimento de prazos e burocracia } \\
\text { - Falta de objetivos claros } \\
\text { - Insuficiência de políticas de investimentos na escola }\end{array}$ & 13 & 15 & 28 & 34,15 \\
\hline $\begin{array}{l}\text { - DE NATUREZA PEDAGÓGICA RELACIONADOS À ESCOLA } \\
\text { - Equipe escolar não possui conhecimento sobre criatividade } \\
\text { - Concepção de criatividade ligada à arte } \\
\text { - Proposta pedagógica construída de forma inadequada } \\
\text { - Escola conteudista, reprodutivista } \\
\text { - Escola poda, embota a criatividade da criança } \\
\text { - As crianças já recebem as coisas prontas, não se oportuniza } \\
\text { a criatividade }\end{array}$ & 6 & 7 & 13 & 15,85 \\
\hline $\begin{array}{l}\rightarrow \text { DE NATUREZA PESSOAL RELACIONADOS AO ALUNO } \\
\text { - Indisciplina } \\
\text { - Falta de vínculo com a escola, e interesse } \\
\text { - Resistência do aluno às normas }\end{array}$ & 0 & 4 & 4 & 4,87 \\
\hline Total & 35 & 47 & 82 & $100 \%$ \\
\hline
\end{tabular}

Nota: A porcentagem foi calculada conforme o número de respostas emitidas por gestores e orientadores educacionais e não a partir do número de entrevistados.

\section{Percepção de gestores e orientadores educacionais quanto aos elementos que têm inibido a implementação de práticas pedagógicas voltadas para o desenvolvimento da criatividade no contexto escolar}

As respostas apontaram múltiplos elementos inibidores à criatividade (ver Tabela 4). As categorias com maior número de respostas foram as referentes a elementos de natureza "pessoal/pedagógica referentes ao professor" ( $f=$ 37 ) e aos de "natureza administrativa" ( $f=28)$, seguidos dos elementos de "caráter pedagógico relacionados à escola" ( $f$ = 13), elementos estes sinalizados tanto por gestores quanto por orientadores educacionais. Os de "natureza pessoal relacionados ao aluno" estiveram presentes apenas em quatro respostas de orientadores educacionais.

As falas a seguir ilustram algumas das distintas categorias encontradas: 
Tabela 5. Elementos facilitadores à implementação de práticas pedagógicas voltadas para a criatividade segundo gestores e orientadores educacionais.

\begin{tabular}{|c|c|c|c|c|}
\hline & G & O.E & \multicolumn{2}{|c|}{ Total } \\
\hline ELEMENTOS FACILITADORES APONTADOS & f & f & f & $\%$ \\
\hline $\begin{array}{l}\rightarrow \text { DE NATUREZA PESSOAL/PEDAGÓGICA RELACIONADOS AO DOCENTE } \\
\text { - O trabalho com a autoestima, valorização e estímulo ao professor } \\
\text { - Liberdade e autonomia conferidas ao professor na sua prática docente } \\
\text { - Prazer do docente em ensinar } \\
\text { - Interesse e disposição do docente para inovar }\end{array}$ & 10 & 6 & 16 & 51,62 \\
\hline $\begin{array}{l}\rightarrow \text { DE NATUREZA ADMINISTRATIVA } \\
\text { - Constância da equipe de trabalho } \\
\text { - Direção e equipe voltados para o desenvolvimento da criatividade } \\
\text { - Responsabilidades compartilhada. Momento de compartilhamento } \\
\text { de objetivos e propósitos por toda equipe escolar } \\
\text { - Cursos da EAPE viabilizam a atualização e capacitação do professor } \\
\text { - Uma gestão participativa/democrática } \\
\text { - Maior interesse pelas necessidades do aluno por parte da } \\
\text { administração pública (instância superior à escola) }\end{array}$ & 4 & 7 & 11 & 35,48 \\
\hline $\begin{array}{l}\rightarrow \text { DE NATUREZA INTERPESSOAL } \\
\text { - Manter um bom clima e relacionamento } \\
\text { - Trabalhar em equipe }\end{array}$ & 2 & 2 & 4 & 12,90 \\
\hline Total & 16 & 15 & 31 & $100 \%$ \\
\hline
\end{tabular}

Nota: A porcentagem foi calculada conforme o número de respostas emitidas por gestores e orientadores educacionais e não a partir do número de entrevistados.

[...] temos professores muito tradicionais, a atuação deles é mais acadêmica, [...] eu vejo que não acrescenta muito, não acrescenta. (G8)

Tem turmas aqui que trocaram de professor três/quatro vezes durante o ano. Então, por mais boa vontade que esse professor tenha, ele não consegue, porque já pega o trabalho pelo meio do caminho. A gente esbarra muito nessa parte. (G6)

Material é muito difícil, a gente não tem material. Ele é criação nossa. (OE10)

Eu acho que o desenvolvimento da criatividade dentro da escola depende muito do conhecimento da literatura, de como trabalhar, ver se está funcionando. Acho que depende mais do conhecimento em si da criatividade. O que facilitaria nossa vida se tivesse esse conhecimento! (G4)

A escola cumpre muito bem a sua função do conhecimento específico, esse conhecimento apreendido, que é aquele repassado mesmo. Mas deixa de cumprir essa transposição desse apreendido para o aprender mesmo a fazer [...] eu vejo a reprodução pela reprodução [...] (OE8)

Como pode ser observado na Tabela 4, para os entrevistados, o maior número de barreiras relacionava-se ao professor e às questões administrativas. O desestímulo, o desânimo, a falta de capacitação profissional, o conservadorismo, o medo do novo, a desvalorização, entre outros aspectos inerentes ao professor, foram apontados como elementos dificultadores ao desenvolvimento da criatividade.

Quanto às barreiras de cunho administrativo, um elemento apontado foi a rotatividade de professores durante o ano letivo, aspecto que nos remete a Perrenoud (1999), quando observa que qualquer situação que resulte na fragmentação do tempo e nas intervenções do professor exerce efeitos significativos sobre a regulação das aprendizagens, tendo como consequência o comprometimento da qualidade do trabalho individualizado e diferenciado, já que as intervenções e o processo de construção do professor são interrompidos, ficando, desse modo, inacabados. Tal contexto 
Tabela 6. Elementos apontados por gestores e orientadores educacionais como inibidores, no exercício de suas funções, à promoção de condições favoráveis à criatividade da organização escolar e de seus integrantes.

\begin{tabular}{|c|c|c|c|c|}
\hline & G & O.E & \multicolumn{2}{|c|}{ Total } \\
\hline ELEMENTOS INIBIDORES & $f$ & $f$ & $f$ & $\%$ \\
\hline $\begin{array}{l}\text { - RELATIVOS AO PROFESSOR } \\
\text { - Autonomia em sua prática diária } \\
\text { - Tradicionalismo e inflexibilidade } \\
\text { - Resistência à inovação } \\
\text { - Medo do novo }\end{array}$ & 11 & 1 & 12 & 20,68 \\
\hline $\begin{array}{l}\rightarrow \text { RELATIVOS À FAMÍLIA } \\
\text { - Família ausente } \\
\text { - Família resistente ao novo, conteudista }\end{array}$ & 7 & 3 & 10 & 17,25 \\
\hline $\begin{array}{l}\text { - DE NATUREZA ADMINISTRATIVA } \\
\text { - Substituições constantes de diretores de escola } \\
\text { - Obrigações legais e burocráticas } \\
\text { - Administradores em instância superior conservadores } \\
\text { - Falta de recurso material e pedagógico } \\
\text { - Dificuldade para exercer a democracia }\end{array}$ & 8 & 0 & 8 & 13,79 \\
\hline $\begin{array}{c}\rightarrow \text { DE NATUREZA INTERPESSOAL } \\
\text { - Visão do gestor como um colega }\end{array}$ & 2 & 0 & 2 & 3,45 \\
\hline $\begin{array}{l}\rightarrow \text { RELATIVOS À FUNÇÃO E ATRIBUIÇÕES DO ORIENTADOR } \\
\text { - Desvalorização do trabalho do orientador educacional } \\
\text { - Resistência do professor } \\
\text { - Resistência da direção } \\
\text { - Inexistência de jornada ampliada para o orientador educacional }\end{array}$ & 0 & 14 & 14 & 24,14 \\
\hline $\begin{array}{l}\rightarrow \text { RELATIVOS A VISÕES ERRÔNEAS SOBRE O ORIENTADOR } \\
\text { - Orientador visto como psicólogo } \\
\text { - Orientador visto como quem deve ser capaz de soluções imediatas } \\
\text { - Orientador visto como disciplinador }\end{array}$ & 0 & 12 & 12 & 20,69 \\
\hline Total & 28 & 30 & 58 & $100 \%$ \\
\hline
\end{tabular}

Nota: A porcentagem foi calculada conforme o número de respostas emitidas por gestores e orientadores educacionais e não a partir do número de entrevistados.

remete, ainda, a vários estudiosos da criatividade (Alencar, 2000b, 2002, 2007; Fleith, 2001, 2007; Freire \& Shor, 1996; Güenther, 2000; Morejón, 1996; Starko, 1995; Tardif, 2003; Wechsler, 2001, 2002; Zabalba, 1998) que fazem referência à importância da ação do professor no desenvolvimento do potencial criativo do homem.
Percepção de gestores e orientadores educacionais sobre elementos facilitadores à implementação de práticas pedagógicas voltadas para o desenvolvimento da criatividade no contexto escolar

Como se pode observar na Tabela 5, a categoria com maior número de respostas foi a referente a elementos de 
"natureza pessoal/pedagógica relacionada ao docente" ( $f$ $=16$ ), seguida da relativa a elementos de "natureza administrativa" ( $f=11$ ). Por outro lado, a categoria com menor número de respostas foi a referente a elementos facilitadores de "natureza interpessoal" ( $f=4)$.

Seguem falas ilustrativas de distintas categorias:

Valorizar o professor, tá? Que seja através do dia do professor, por exemplo. Fazer uma homenagem ao professor. [...] Valorizar mais a profissão do professor, ele está se sentindo desvalorizado. (OE8)

[...] o professor tem que gostar do que faz, porque muitas vezes aquele que não gosta do que faz não vai ser criativo, com certeza ele não vai conseguir. (OE7)

[...] essa equipe constante, há mais tempo congregando esses ideais, vivendo essas diferenças, debatendo, contrapondo pontos de vista, eu vejo que ao longo do processo flui algo enriquecedor, [...] nossas diferenças somam algo positivo. (G8)

A postura da direção pode tanto acabar com o trabalho quanto engrandecer o trabalho. Por isso é necessário uma gestão mais participativa, democrática. [...] (OE4)

Observou-se, durante as entrevistas, que tanto os gestores quanto os orientadores educacionais, de modo geral, tiveram dificuldades para expressar elementos facilitadores à implementação de práticas pedagógicas voltadas para a criatividade. O contrário aconteceu quando lhes foi perguntado sobre os elementos inibidores, denotando a força desses diante dos facilitadores, o que vem reforçar a ideia de que a escola, por diversas razões, ainda não se configura como um ambiente favorecedor ao desenvolvimento da criatividade. Além disso, embora os entrevistados fossem inquiridos a respeito dos elementos facilitadores em primeiro lugar, na maioria das vezes, começavam por relacionar os inibidores. Ademais, "valorizar o professor" foi um aspecto apontado de forma veemente por alguns participantes ao responderem sobre elementos facilitadores à implementação de práticas pedagógicas voltadas para o desenvolvimento da criatividade no contexto escolar, sugerindo, a nosso ver, a percepção de que o professor, ao se sentir valorizado, reage positivamente em suas ações educativas.

\section{Percepção de gestores e orientadores educacionais sobre elementos que inibem, no exercício de suas funções, a promoção de condições favoráveis ao desenvolvimento da criatividade da organização escolar e de seus integrantes.}

Uma análise dos resultados indicou, conforme Tabela 6 , que tanto gestores quanto orientadores educacionais apontaram, em suas respostas, elementos inibidores relativos aos "professores" ( $f=12$ ) e à "família" ( $f=10)$, ao passo que os de "natureza administrativa" ( $f=8$ ) e os de "natureza interpessoal" ( $f=2$ ) foram indicados somente por gestores. Por outro lado, os orientadores educacionais consideraram como inibidores elementos relacionados à sua função e atribuições $(f=14)$ e visões errôneas sobre seu papel $(f=12)$.

Seguem exemplos de respostas que ilustram distintas categorias:

O professor pega aquele caderninho ali, parece que coloca um tampão nos ouvidos e trabalha como se trabalhasse há quinze/vinte anos atrás. É muito tradicional. (G9)

[...] às vezes a dificuldade é que o professor acha tudo muito assustador. Ele tem medo das coisas novas, ele tem medo de se jogar de corpo e alma numa coisa nova, [...] parece que tem medo do novo, da modernidade, fica naquela mesmice que até a gente chama assim: "Você é professora, Gabriela? Eu nasci assim, eu cresci assim, vou ser sempre assim." (OE8)

[...] os pais não vêm aqui. Eu tenho pai e mãe que só vêm atrás do filho porque ela tá preocupada que o filho faltou três dias e vão cortar o Renda Mínima dela. Ela não pergunta como o filho tá, como foi, o que ele fez. (G4)

[...] ao longo de seis anos vem tendo uma quebra, cada um (gestor) fica um ano. Então isso se perdeu, isso tem dificultado a escola andar, crescer. Tem dificultado bastante. (G5)

Nós encontramos resistências de alguns diretores, [...] principalmente se, na escola, você não é bem recebida e quando a direção não gosta de orientadores. [...] (OE2)

[...] então eles acham que eu sou psicólogo e que eles não precisam de psicólogo [...] e não precisa vir até aqui porque não está com problemas mentais, digamos assim, [...] essa ideia é muito antiga, muito enraizada nos professores. (OE8)

Chamou-nos atenção o fato de que, ao se referirem à família, vários participantes apontaram que ela se constitui em elemento negativo ao desenvolvimento de seus filhos e da própria escola, já que a equipe escolar não pode contar com o apoio dos pais. Ressaltaram, ainda, que a família deixa a cargo da escola a educação informal, como tratos pessoais, higiene, comportamentos sociais, entre outros, formação que deveria partir de casa e não exclusivamente da escola. Os respondentes consideraram que o tempo despendido com essas atividades faz com que elementos importantes como, por exemplo, o desenvolvimento da criatividade no contexto escolar, sejam deixados de lado. Além disso, lembraram que falta o apoio familiar necessário para que as atividades propostas na escola, com vistas a desenvolver a criatividade dos alunos, tenham continuidade fora dela.

Por outro lado, ao se referirem ao professor, vários gestores consideraram a autonomia docente como elemento 
Tabela 7. Elementos apontados por gestores e orientadores educacionais como facilitadores, no exercício de suas funções, à promoção de condições favoráveis à criatividade da organização escolar e de seus integrantes.

\begin{tabular}{|c|c|c|c|c|}
\hline & $G$ & O.E & \multicolumn{2}{|l|}{ Total } \\
\hline ELEMENTOS FACILITADORES & $f$ & $f$ & $f$ & $\%$ \\
\hline $\begin{array}{l}\rightarrow \text { RELATIVOS ÀS FUNÇÕES DO GESTOR E DO ORIENTADOR } \\
\text { EDUCACIONAL } \\
\text { - A posição de gestor } \\
\text { - Coordenar, articular o grupo } \\
\text { - Trabalhar coletivamente } \\
\text { - Buscar parcerias } \\
\text { - Realizar planejamentos individuais } \\
\text { - Planejar coletivamente } \\
\text { - Estar fora da sala de aula } \\
\text { - Servir de ponto de apoio ao docente } \\
\text { - Trabalhar com os alunos }\end{array}$ & 9 & 5 & 14 & 41,17 \\
\hline $\begin{array}{l}\rightarrow \text { RELATIVOS AO RELACIONAMENTO INTERPESSOAL } \\
\text { - Preservar um bom relacionamento } \\
\text { - Caminhar de modo que não machuque as pessoas } \\
\text { - Incentivar e estimular o grupo } \\
\text { - Conversar, discutir, não impor }\end{array}$ & 6 & 0 & 6 & 17,63 \\
\hline $\begin{array}{l}\rightarrow \text { RELATIVOS À EQUIPE DE TRABALHO } \\
\text { • A disposição e o suporte oferecidos pela equipe }\end{array}$ & 3 & 0 & 3 & 8,87 \\
\hline $\begin{array}{l}\text { T RELATIVOS ÀS CARACTERÍSTICAS PESSOAIS DO } \\
\text { ORIENTADOR EDUCACIONAL } \\
\text { - Gostar do que faz } \\
\text { - Ser persistente } \\
\text { - Ter visão mais atualizada, abrangente do papel do OE } \\
\text { - Fazer-se respeitar pela firmeza e profissionalismo }\end{array}$ & 0 & 6 & 6 & 17,63 \\
\hline $\begin{array}{l}\rightarrow \text { RELATIVOS AO DOCENTE } \\
\text { - A busca pelo SOE } \\
\text { - A crença de que o orientador educacional tem algo a oferecer }\end{array}$ & 0 & 5 & 5 & 14,70 \\
\hline Total & 18 & 16 & 34 & $100 \%$ \\
\hline
\end{tabular}

Nota: A porcentagem foi calculada conforme o número de respostas emitidas por gestores e orientadores educacionais e não a partir do número de entrevistados.

inibidor da criatividade, uma vez que o professor tem total liberdade em sala de aula para atuar da forma como desejar, mesmo quando o gestor apresenta sugestões com o objetivo de melhorar a prática docente. Citaram, ainda, a inflexibilidade e o tradicionalismo do professor como elementos que o tornam conservador e difícil de lidar quando se trata de acatar novas propostas, já que, muitas vezes, consideram que o gestor está, nas palavras de G4, "inventando coisas".
Percepção de gestores e orientadores educacionais sobre elementos facilitadores, no exercício de suas funções, à promoção de condições favoráveis ao desenvolvimento da criatividade da organização escolar e de seus integrantes

Conforme apresentado na Tabela 7, a categoria com maior número de respostas foi "elementos relativos às funções do gestor e do orientador educacional”, com 14 respos- 
tas. Por outro lado, elementos "relativos ao relacionamento interpessoal" ( $f=6)$ e à "equipe de trabalho" ( $f=3$ ) foram mencionados apenas por gestores, ao passo que somente orientadores educacionais fizeram referência aos elementos de "natureza pessoal" inerentes aos mesmos $(f=6)$ e "relativos ao docente" ( $f=5)$.

Seguem respostas ilustrativas de algumas das distintas categorias:

O que facilita realmente é a posição que eu estou hoje (orientação). É mais fácil porque você reúne os professores, o grupo e planta uma sementinha, estimula. É mais fácil. (OE4)

A nossa função, o nosso estar fora de sala de aula facilita, [...] eu acho que por ele (o orientador) estar fora de sala de aula você pode lidar com vários segmentos da escola e isso favorece muito. (OE9)

[...] primeira coisa é que eu sou muito respeitada como profissional, porque eu sou muito forte nas minhas colocações. Sou muito profissional. (OE8)

No tocante aos elementos facilitadores, apenas os "relativos às funções do gestor e do orientador educacional" foram destacados por ambos, denotando que, embora tenham uma formação acadêmica semelhante e atuem no mesmo espaço físico, eles possuem ângulos de visão diferenciados das inúmeras situações vivenciadas na escola. Assim, por exemplo, os elementos facilitadores relativos ao "relacionamento interpessoal" e à "equipe de trabalho" foram apontados somente por gestores, o que fortalece a importância do bom relacionamento em favor de uma gestão que busca a qualidade e a eficácia.

\section{Conclusões}

Ao se delinear um quadro ilustrativo referente à concepção de gestores e orientadores educacionais acerca da criatividade, pretendeu-se estimular a busca por alternativas que permitam a implementação de práticas pedagógicas voltadas para o seu desenvolvimento no contexto escolar, pois, conforme ressaltam Alencar e Fleith (2003), apesar do reconhecimento da importância da criatividade e da necessidade de se estimular as habilidades criativas dos alunos, nem mesmo o currículo dos cursos de formação de professores privilegia esta área do conhecimento como meio de prepará-los para lidar com este fenômeno humano no contexto escolar, fato corroborado pelos resultados da presente pesquisa que visualizou tal despreparo.

Recordando palavras de Amabile (1999, p. 110), "quando lembro de todas as organizações que estudei e com as quais trabalhei nos últimos 22 anos, não tenho dúvida: é muito mais frequente ver a criatividade ser destruída do que estimulada, [...] sufocar a criatividade é fácil, difícil é estimulá-la". Infelizmente, os resultados deste estudo não foram contrários ao posicionamento dessa autora, mas confirmaram sua percepção a respeito das organizações. Existe o veemente reconhecimento, por parte dos entrevistados, da necessidade do ser criativo para saber lidar com as exigências do mundo atual, que consideramos desafiador, pois traz consigo grandes avanços tecnológicos, rapidez e acúmulo de informações geradas diariamente, provocando transformações de natureza política, econômica, cultural, demandando um incessante fluxo de mudanças nos diferentes segmentos sociais, levando, assim, à valorização do potencial criador humano. Contudo, contraditoriamente, a equipe escolar pesquisada não está capacitada a implementar práticas pedagógicas que formem o cidadão para intervir na realidade desse momento histórico. Assim, diante dessa situação, a criatividade tende a ser sufocada. No entanto, a incapacidade para implementar tais práticas não decorre, precisamente, da inabilidade do profissional da educação para lidar com esse fenômeno, mas da sua desinformação decorrente, ao menos em parte, da inobservância do currículo do Curso de Pedagogia sobre a importância de iluminar os caminhos do educador com teorias acerca desse fenômeno, para que, desperto para sua significância, possa buscar o aperfeiçoamento necessário.

Diante desse contexto, as autoras do presente estudo consideram que a educação precisa se libertar da sua condição reprodutivista, que não contribui com o pensamento divergente que se constitui em um elemento essencial quando se trata de desenvolver o potencial criativo humano. Para começar, é necessário um investimento emergencial na capacitação dos educadores para que possam lidar com a criatividade no contexto escolar de forma eficiente e consciente e, desse modo, contribuir para que uma nova era educativa se inicie, a era dos tempos em que a educação se encontrará diretamente articulada às reais necessidades do educando e da sociedade na qual se insere, o que aliás é um dos seus propósitos.

O gestor tem uma posição central que sustenta o bom andamento das atividades, a eficácia organizacional e o sucesso das ações planejadas. Assim, para desenvolver a criatividade no contexto escolar, é necessário que esse profissional conheça a cultura organizacional e os recursos disponíveis - humanos e materiais -, assim como a comunidade na qual a escola se insere. O gestor deve, ainda, como suporte às suas ações, buscar informações acerca de experiências bem sucedidas em organizações escolares e, sobretudo, conhecer técnicas de apoio a uma gestão que tem como meta alcançar o sucesso de todos.

Quanto ao orientador educacional, sua função ultrapassa os muros da escola, pois ele tem, como uma de suas tarefas, participar do processo de integração famíliaescola-comunidade, uma ação importante para a melhoria dos padrões educacionais, visto que, desse modo, podem apoiar-se mutuamente em busca do bem comum. Por sua vez, o professor é reconhecido como uma peça chave do processo educacional e é, conforme Güenther (2000), entre os vários possíveis observadores presentes naturalmente na vida de uma criança, o que aparece como uma figura de fren- 
te e que convive diariamente com ela, em situações as mais variadas, em uma dimensão de tempo considerável. Daí a necessidade de capacitar a equipe escolar para que juntos promovam a articulação entre aluno, escola e sociedade, de modo que, buscando o bem comum, atinjam o crescimento, o desenvolvimento e a evolução.

Sabe-se que as mazelas e os desafios educacionais no Brasil são inúmeros e não raramente causam angústia e desânimo aos que se inserem nesse contexto. Contudo, conforme Gomes (2002, p. 7), "se isso serve de consolo, tais angústias e lágrimas não se restringem aos países em desenvolvimento, que enfrentam crônica escassez de meios para prover a educação que consideram necessária".

Portanto, se educadores se dispõem a trilhar os caminhos tortuosos da educação, com seus problemas micros e macros, com toda a sua diversidade, complexidade, ambiguidade e iniquidade, não devem desanimar com facilidade, devem buscar o otimismo, a esperança e a vontade de "ampliar a visão e assumir uma atitude construtiva em face dos desafios, que não são poucos" (Gomes, 2002, p. 8).

$\mathrm{Na}$ impossibilidade de uma só pesquisa açambarcar todos os aspectos que merecem ser investigados acerca da relação criatividade e escola, sugerimos que estudos posteriores repliquem a presente pesquisa em escolas particulares, acrescida de uma análise documental dos Projetos Políticos Pedagógicos, com vistas a reconhecer, em seus objetivos e propostas, aspectos que privilegiem o desenvolvimento da criatividade no contexto escolar, de modo a atender às demandas sociais vigentes.

\section{Referências}

Alencar. E. L. M. S. (1996). A gerência da criatividade. São Paulo: MAKRON.

Alencar, E. M. L. S. (2000a). O processo da criatividade. São Paulo: Makron.

Alencar, E. M. L. S. (2000b). O perfil do professor facilitador e do professor inibidor da criatividade segundo estudantes de pósgraduação. Boletim da Academia Paulista de Psicologia, 19, 8494.

Alencar, E. M. L. S. (2002). O contexto educacional e sua influência na criatividade. Linhas Críticas, 8, 165-178.

Alencar, E. M. L. S. (2007). O papel da escola na estimulação do talento criativo. Em D. S. Fleith \& E. M. L. S. Alencar (Orgs.), Desenvolvimento de talentos e altas habilidades. Orientação a pais e professores (pp. 151-162). Porto Alegre: ArtMed.

Alencar, E. M. L. S. (2009). Como desenvolver o potencial criador (11a ed.). Petrópolis, RJ: Vozes.

Alencar, E. M. L. S., \& Fleith, D. S. (2003). Criatividade - múltiplas perspectivas. Brasília: Editora da Universidade de Brasília.
Amabile, T. M. (1999). Como não matar a criatividade. HSM Management, 3, 110-117.

Bardin, L. (1995) Análise de conteúdo. Lisboa: Edições 70.

Bauer, M. W., \& Gaskell, G. (2002). Pesquisa qualitativa com texto, imagem e som: um manual prático. Petrópolis, RJ: Vozes.

Brasil (1996). Lei 9.394/96, de 20 de dezembro de 1996. Estabelece as Diretrizes e Bases da Educação Nacional. Diário Oficial da União, Brasília, DF, 23 dez. 1996.

Castells, M. (1999). A era da informação: economia, sociedade e culturas. Fim de milênio. (Vol. III) (3a ed.). Rio de Janeiro: Paz e Terra.

Castells, M. (2003). A era da informação: economia, sociedade e culturas. (Vol. I) (7a ed.). Rio de Janeiro: Paz e Terra.

Craft, A. (2005). Creativity in schools: tensions and dilemmas. London: Routledge.

Craft, A. (2007). Creativity in schools. Em N. Jackson, M. Oliver, M. Shaw \& J. Wisdom (Orgs.), Developing creativity in higher education (pp. 19-28). London: Routledge.

Csikszentmihalyi, M. (1994). The domain of creativity. Em D. H. Feldman, M. Csikszentmihalyi \& H. Gardner (Orgs.), Changing the world: a framework for the study of creativity (pp. 135-158). Westport: Praeger.

Cropley, A. J. (1997). Fostering creativity in the classroom: general principles. Em M. A. Runco (Org.), The creativity research handbook (pp. 83-114). Creskill, NJ: Hampton Press.

Cropley, A. J. (2005). Creativity in education \& learning. London: RoutledgeFalmer.

Edwards, M., McGoldrick, C., \& Oliver, M. (2007). Creativity and curricula in higher education: academic's perspectives. Em N. Jackson, M. Oliver, M. Shaw \& J. Wisdom (Orgs.), Developing creativity in higher education (pp. 59-73). London: Routledge.

Feldman, D. H., Csikszentmihalyi, M., \& Gardner, H. (1994). Changing the world. A framework for the study of creativity. Westport: Praeger Publishers.

Fleith, D. S. (2001). Criatividade: novos conceitos e ideias, aplicabilidade à educação. Cadernos de Educação Especial, 17, 55-61.

Fleith, D. S. (2007). Como desenvolver a criatividade no contexto educacional. Em SESI - Departamento Nacional (Org.). Criatividade (pp. 9-30). Brasília: SESI - Departamento Nacional.

Franco, M. L. P. B. (2005). Análise do conteúdo. Brasília: LiberLivro. 
Freire, P., \& Shor, I. (1996). Medo e ousadia - o cotidiano do professor. São Paulo: Paz e Terra.

Gilson, L. L. (2008). Why be creative: a review of the practical outcomes associated with creativity at the individual, group, and organizational levels. Em J. Zhou \& C. E. Shalley (Orgs.), Handbook of organizational creativity (pp. 303-322). New York: Lawrence Erlbaum.

Gomes, C. A. (2002). Gestão educacional: o Brasil no mundo contemporâneo. Em Aberto, 19, n. 75, 7-8.

Güenther, Z. (2000). Desenvolver capacidades e talentos: um conceito de inclusão. Petrópolis, RJ: Vozes.

Hill, D. (2003). O neoliberalismo global, a resistência e a deformação da educação. Currículo sem Fronteiras, 3, 24-59. [On-line]. Disponível em http://curriculosemfronteiras.org/artigos. Acesso em 15 mar 2006.

Jackson, N., Oliver, M. Shaw, M., \& Wisdom, J. (Orgs.). (2007). Developing creativity in higher education. London: Routledge.

Lück, H. (Org). (2000). Gestão Escolar e formação de gestores. Em Aberto, 72, 11-32.

Lück, H. e cols. (2001). A escola participativa: o trabalho do gestor escolar. Rio de Janeiro: DP\&A.

Martínez, A. M. (2002). A criatividade na escola: três direções de trabalho. Linhas Críticas, 8, 189-206.

Martínez, A. M. (2003). Criatividade, personalidade e educação. São Paulo: Papirus.

Martínez, A. M. (2006). Criatividade no trabalho pedagógico e criatividade na aprendizagem: uma relação necessária? Em M. C. V. R. Tacca (Org.), Aprendizagem e trabalho pedagógico (pp. 6994). Campinas, SP: Alínea.

Morejón, J. B. (1996). Psicología y creatividad: apuntes y reflexiones. Guadalajara: Editorial de la Universidad de Guadalajara.

Nakano, T. G., \& Wechsler, S. M. (2007). Identificação e avaliação do talento criativo. Em D. S. Fleith \& E. M. L. S. Alencar (Orgs.), Desenvolvimento de talentos e altas habilidades. Orientação a pais e professores (pp. 87-98). Porto Alegre: ArtMed.

Ortiz, R. (1994). Mundialização e cultura. São Paulo: Cultrix.

Perrenoud, P. (1999). Avaliação, da excelência à regulação das aprendizagens: entre duas lógicas. Porto Alegre: Artes Médicas.
Prado-Diez, D. de. (1999). Analogía inusual. Colección Monografías Master de Creatividad. Servicio de Publicacións e Intercambio Científico. Santiago de Compostela: Universidade de Santiago de Compostela.

Richardson, R. J. (1999). Pesquisa social - métodos e técnicas. São Paulo: Atlas.

Rifkin, J. (2000). Laera del acceso: la revolución de la nueva economía. Barcelona: Paidós.

Runco, M. A. (2007). Creativity. Theories and themes: Research, development, and practice. Burlington, MA: Elsevier.

Sawyer, R. K. (2006). Explaining creativity. The science of human innovation. New York: Oxford University Press.

Shalley, C. E. (2008) Handbook of organizational creativity. New York: Lawrence Erlbaum.

Smith-Bingham, R. (2007). Public policy, innovation and the need for creativity. Em N. Jackson, M. Oliver, M. Shaw \& J.Wisdom (Orgs.), Developing creativity in higher education (pp. 10-18). London: Routledge.

Starko, A. J. (1995). Creativity in the classroom. White Plains, NJ: Longman.

Tardif, M. (2003). Saberes docentes e formação profissional. Petrópolis, RJ: Vozes.

Touraine, A. (1994). Crítica da modernidade. Lisboa: Instituto Piaget.

Wechsler. S. M. (2001). A educação criativa: possibilidade para descobertas. Em S. Castanho \& M. E. Castanho (Orgs.), Temas e textos em metodologia do Ensino Superior (pp.165-170). Campinas, SP: Papirus.

Wechsler. S. M. (2002). Criatividade: descobrindo e encorajando. Contribuições teóricas e práticas para as mais diversas áreas. Campinas: Livro Pleno.

Zabalza, M. A. (1998). Qualidade em Educação Infantil. Porto Alegre: Artmed.

Zhou, J., \& Sawyer, R. K. (2006). Explaining creativity. The science of human innovation. New York: Oxford University Press. 
Recebido em: 12/08/2009

Reformulado em: 31/05/2010

Aprovado em: 08/07/2010

Sobre as autoras

Eny da Luz Lacerda Oliveira (enydlo@terra.com.br) Universidade Católica de Brasília, Brasília-DF

Eunice Maria Lima Soriano de Alencar (ealencar@pos.ucb.br)

Universidade Católica de Brasília, Brasília-DF

\section{Correspondência:}

Eunice Maria Lima Soriano de Alencar

Programa de Pós-Graduação em Educação - Universidade Católica de Brasília SGAN 916 Módulo B Asa Norte, CEP: 70.790-160 Brasília-DF 